\title{
A Remarkable Elevation in the Procalcitonin Levels Due to Diabetic Ketoacidosis in a Hemodialysis Patient
}

\author{
Shohei Fukunaga ${ }^{1}$, Yuki Hoshino ${ }^{1}$, Hirotaka Sonoda ${ }^{1}$, Miharu Kawanishi ${ }^{1}$, Asuka Yamauchi ${ }^{1}$, \\ Shiho Kato ${ }^{1}$, Kaori Yoshikane ${ }^{1}$, Hiroaki Shiina ${ }^{2}$, Kazuaki Tanabe ${ }^{1}$ and Takafumi Ito ${ }^{1}$
}

\begin{abstract}
:
Procalcitonin (PCT), a marker of the inflammatory response during infections, can be elevated by diabetic ketoacidosis (DKA). A male patient in his 50s with diabetic nephropathy on hemodialysis presented with vomiting and a reduced level of consciousness and was diagnosed with DKA. His PCT level was markedly elevated, but bacterial cultures (blood, urine, and stool) were negative. The PCT level decreased after DKA improvement. In this patient, DKA probably enhanced the PCT levels. As DKA can increase the PCT levels, an elevation of the PCT levels in DKA patients may not be indicative of infectious diseases, and noninfectious causes of DKA should therefore be considered.
\end{abstract}

Key words: procalcitonin, diabetic ketoacidosis, hemodialysis

(Intern Med 60: 1231-1235, 2021)

(DOI: 10.2169/internalmedicine.5841-20)

\section{Introduction}

Diabetic ketoacidosis (DKA) is one of the most serious complications of diabetes mellitus (DM). It often manifests in type 1 and type $2 \mathrm{DM}$. Infections are the most common triggers of DKA. Several studies have reported that DKA enhances cytokine production (1-3). The procalcitonin (PCT) levels increase in bacterial infections/sepsis and they are used as markers of bacterial infection (4). However, they can also increase in conditions that elevate the cytokine levels, such as burns, trauma, surgery, and pancreatitis (5). A few studies have reported that PCT can increase in DKA. However, the mechanism by which DKA leads to elevated PCT levels remains unknown. To the best of our knowledge, only one report has quantified the PCT levels in DKA (6). Understanding the transition in the PCT level is important for elucidating the relationship between PCT and DKA. In this case report, we measured the PCT levels twice (during and after DKA). Importantly, this is the first report on the relationship between PCT and DKA in patients on hemodialysis (HD). Specifically, we herein present the case of a patient on HD with DKA who had markedly elevated PCT levels, and we assessed the relationship between PCT and DKA.

\section{Case Report}

A male patient in his 50 s presented to our hospital with vomiting, a reduced level of consciousness, and malaise that had developed 2 days prior to admission. He had been receiving treatment for type $1 \mathrm{DM}$ for 34 years and HD for end-stage kidney disease due to diabetic nephropathy for 6 years. He had received online-hemodiafiltration (HDF) 2 days before admission. He was on insulin therapy (insulin glargine: $10 \mathrm{U}$ at bedtime; insulin aspart: $6 \mathrm{U}$ at breakfast, lunch, and dinner time), although he stopped the insulin therapy the day before admission. His regular medications were rabeprazole sodium, precipitated calcium carbonate, bixalomer, alfacalcidol, amitriptyline hydrochloride, and atorvastatin calcium hydrate. The initial physical examination showed a blood pressure of $100 / 51 \mathrm{mmHg}$, a heart rate of 80 beats/min, and an oxygen saturation of $99 \%$ (room air). His height, body weight, and body mass index were $163 \mathrm{~cm}, 57.6 \mathrm{~kg}$, and $21.7 \mathrm{~kg} / \mathrm{m}^{2}$, respectively. His respiratory sounds were clear, and no abnormal abdominal findings were noted. Blood investigations (Table 1) showed severe

${ }^{1}$ Department of Internal Medicine IV, Shimane University Faculty of Medicine, Japan and ${ }^{2}$ Department of Urology, Shimane University Faculty of Medicine, Japan

Received: July 11, 2020; Accepted: September 23, 2020; Advance Publication by J-STAGE: November 23, 2020

Correspondence to Dr. Shohei Fukunaga, fukunaga@med.shimane-u.ac.jp 
Table 1. Laboratory Investigation.

\begin{tabular}{|c|c|c|c|c|c|c|c|}
\hline \multicolumn{2}{|c|}{ Hematology } & \multicolumn{4}{|c|}{ Blood chemistry } & \multicolumn{2}{|c|}{ Blood gas (arterial blood) } \\
\hline WBC & $14,530 / \mu \mathrm{L}$ & $\mathrm{TP}$ & $6.8 \mathrm{~g} / \mathrm{dL}$ & $\mathrm{Na}$ & $124 \mathrm{mmol} / \mathrm{L}$ & $\mathrm{pH}$ & 7.019 \\
\hline Neut & $95.5 \%$ & Alb & $3.6 \mathrm{~g} / \mathrm{dL}$ & K & $7.8 \mathrm{mmol} / \mathrm{L}$ & $\mathrm{PCO}_{2}$ & $26.4 \mathrm{mmHg}$ \\
\hline Lynph & $0.5 \%$ & T-bil & $0.1 \mathrm{mg} / \mathrm{dL}$ & $\mathrm{Cl}$ & $88 \mathrm{mmol} / \mathrm{L}$ & $\mathrm{PO}_{2}$ & $82.1 \mathrm{mmHg}$ \\
\hline Mono & $4 \%$ & AST & $24 \mathrm{U} / \mathrm{L}$ & $\mathrm{Ca}$ & $8.9 \mathrm{mg} / \mathrm{dL}$ & $\mathrm{HCO}_{3}^{-}$ & $8.0 \mathrm{mmol} / \mathrm{L}$ \\
\hline $\mathrm{RBC}$ & $391 \times 10^{4} / \mu \mathrm{L}$ & ALT & $17 \mathrm{U} / \mathrm{L}$ & $\mathrm{P}$ & $6.2 \mathrm{mg} / \mathrm{dL}$ & $\mathrm{Lac}$ & $4.8 \mathrm{mEq} / \mathrm{L}$ \\
\hline $\mathrm{Hb}$ & $12.0 \mathrm{~g} / \mathrm{dL}$ & LDH & $238 \mathrm{U} / \mathrm{L}$ & CRP & $6.38 \mathrm{mg} / \mathrm{dL}$ & & \\
\hline Plt & $10.5 \times 10^{4} / \mu \mathrm{L}$ & $\gamma$-GTP & $7 \mathrm{U} / \mathrm{L}$ & PCT & $62.84 \mathrm{ng} / \mathrm{mL}$ & & \\
\hline \multicolumn{2}{|c|}{ Coagulation } & Alp & $319 \mathrm{U} / \mathrm{L}$ & PG & 767 mg/dL & & \\
\hline PT-INR & 1.00 & BUN & $100.9 \mathrm{mg} / \mathrm{dL}$ & 3-OHBA & $4.3 \mathrm{mmol} / \mathrm{L}$ & & \\
\hline APTT & $29.4 \mathrm{~s}$ & Crea & $12.46 \mathrm{mg} / \mathrm{dL}$ & CPR & $<0.01 \mathrm{ng} / \mathrm{mL}$ & & \\
\hline Fib & $646 \mathrm{mg} / \mathrm{dL}$ & & & & & & \\
\hline D dimer & $0.6 \mu \mathrm{g} / \mathrm{mL}$ & & & & & & \\
\hline
\end{tabular}

3-OHBA: 3-Hydroxybutyric acid, Alb: albumin, Alp: alkaline phosphatase, ALT: alanine aminotransferase, APTT: activated partial thromboplastin time, AST: aspartate aminotransferase, BUN: blood urea nitrogen, CPR: C-peptide immunoreactivity, Crea: creatinine, CRP: C-reactive protein, Fib: fibrinogen, Hb: hemoglobin, Lac: lactate, LDH: lactate dehydrogenase, Lymph: lymphocytes, Mono: monocytes, Neut: neutrophils, PCT: procalcitonin, PG: plasma glucose, Plt: platelet, PT-INR: prothrombin time international normalized ratio, RBC: red blood cells, T-bil: total-bilirubin, TP: total protein, WBC: white blood cells, $\gamma$-GTP: $\gamma$-glutamyl transpeptidase

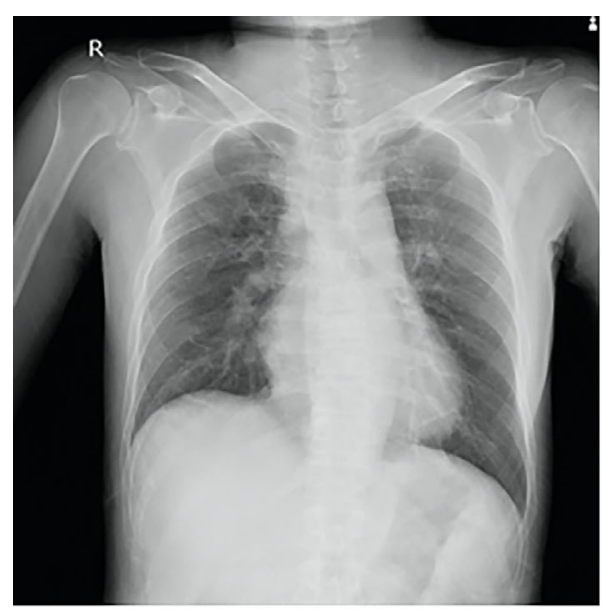

Chest X-ray

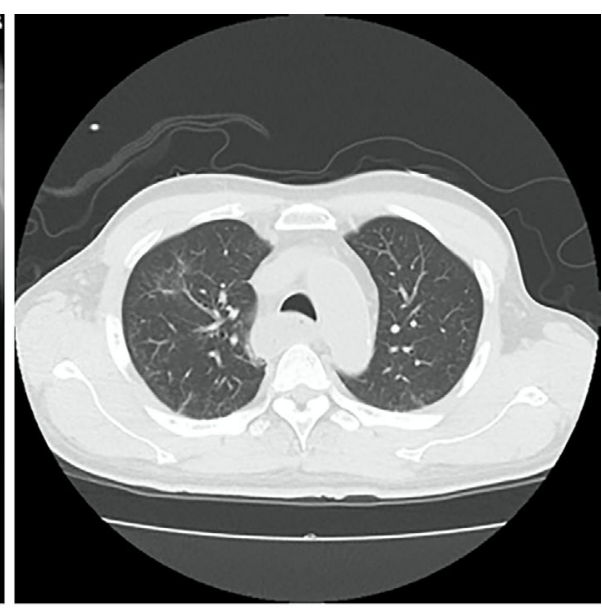

Chest CT

Figure 1. Chest X-ray and computed tomography.

metabolic acidosis, hyperkalemia, hyponatremia, high PCT levels $(62.84 \mathrm{ng} / \mathrm{mL})$, hyperglycemia $(767 \mathrm{mg} / \mathrm{dL})$, and elevated 3-hydroxybutyric acid levels. Therefore, we diagnosed him with DKA, attributed to the cessation of insulin therapy. An electrocardiogram showed normal $\mathrm{P}$ and inverted $\mathrm{T}$ waves. Chest X-ray imaging (Fig. 1) showed no pneumonia, whereas chest computed tomography (CT) showed a very mild frosted glass image on the ventral side of the right lung (in S1). Therefore, we diagnosed him as having slight pneumonia.

Calcium gluconate hydrate $(1,700 \mathrm{mg})$ was injected intravenously, glucose insulin therapy was started, and emergency HD [polyethersulfone (PES) membrane; membrane surface area, $1.5 \mathrm{~m}^{2}$; blood flow, $150 \mathrm{~mL} / \mathrm{min}$; dialysis time, $4 \mathrm{~h}$ ] was urgently performed to manage hyperkalemia. Maintenance hemodialysis (offline-HDF; PES membrane; membrane surface area, $2.1 \mathrm{~m}^{2}$; blood flow, $200 \mathrm{~mL} / \mathrm{min}$; di- alysis time, $4 \mathrm{~h}$ ) was started on the 2 nd day. The continuous intravenous administration of insulin was initiated for managing DKA but was discontinued because of appetite improvement 3 days after admission. Subsequently, intensive insulin therapy was initiated.

A high inflammatory response [C-reactive protein (CRP) levels, $6.38 \mathrm{mg} / \mathrm{dL}$; PCT levels, $62.84 \mathrm{ng} / \mathrm{mL}$ ] was observed (Fig. 2). However, chest CT showed only a slight frosted glass image, and cultures for blood, urine, and stool were negative. We could not perform a sputum culture due to the absence of respiratory symptoms. The intravenous administration of tazobactam/piperacillin $4.5 \mathrm{~g}$ twice daily had been started at admission, but was discontinued on the 4th day; instead, oral sultamicillin $375 \mathrm{mg}$ once daily was initiated. CRP levels rapidly decreased, although his general condition improved. Therefore, we judged that the infection had resolved, and the antibiotics were discontinued on the 


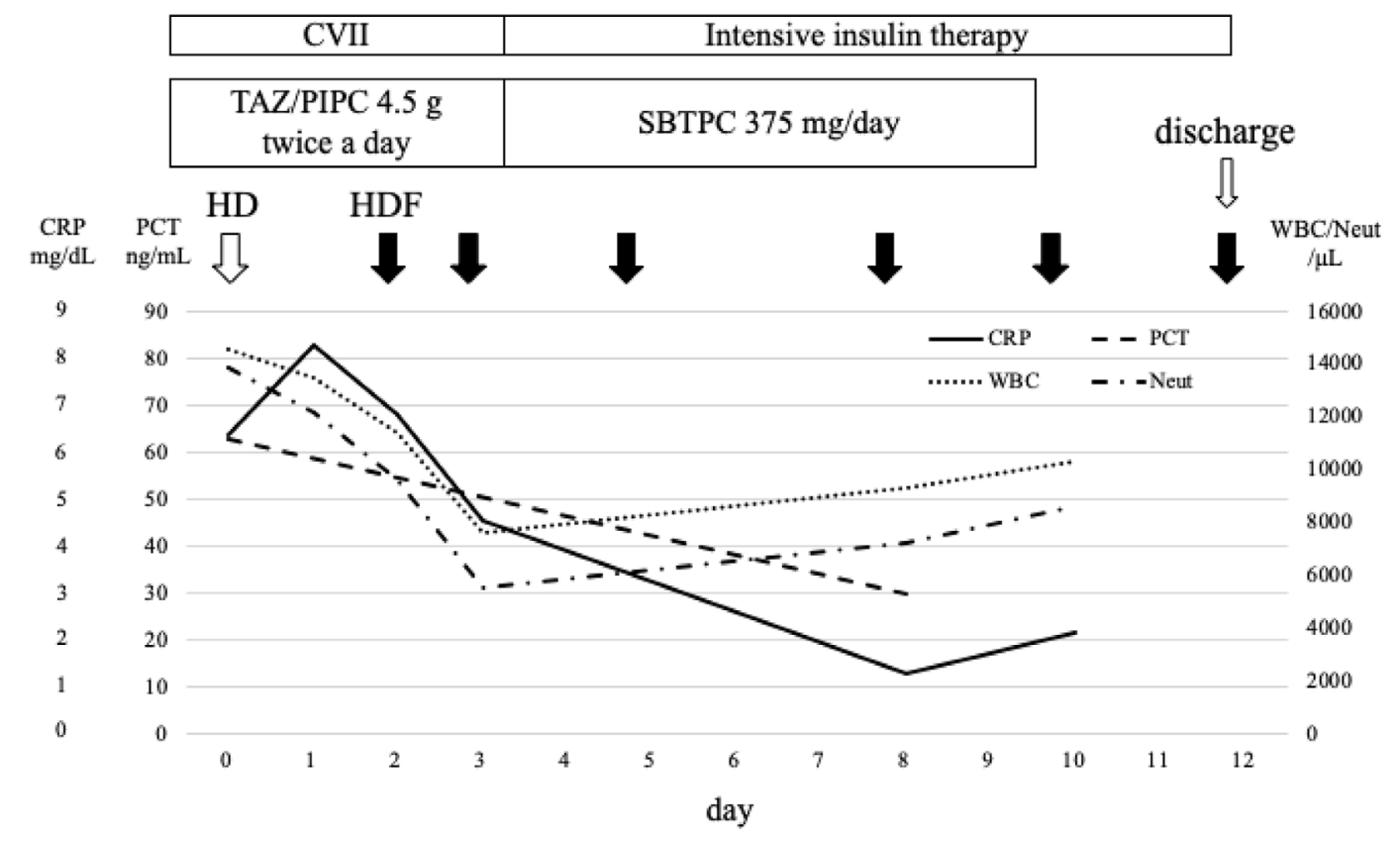

Figure 2. Clinical course of the patient on HD admitted with DKA. CRP: C-reactive protein, CVII: continuous venous insulin infusion, DKA: diabetic ketoacidosis, HD: Hemodialysis, HDF: Hemodiafiltration, Neut: neutrophils, PCT: procalcitonin, SBTPC: sultamicillin, TAZ/PIPC: tazobactam/ piperacillin, WBC: white blood cells

Table 2. Comparison of the Present Case with Previously Reported DKA Patient with High PCT Level.

\begin{tabular}{lcccccccc}
\hline Sex & $\begin{array}{c}\text { Age } \\
(\text { year })\end{array}$ & $\begin{array}{c}\text { Plasma glucose } \\
(\mathrm{mg} / \mathrm{dL})\end{array}$ & $\mathrm{pH}$ & $\begin{array}{c}\text { Lactate } \\
(\mathrm{mEq} / \mathrm{L})\end{array}$ & $\begin{array}{c}\mathrm{WBC} \\
(/ \mathrm{L})\end{array}$ & $\begin{array}{c}\mathrm{CRP} \\
(\mathrm{mg} / \mathrm{dL})\end{array}$ & $\begin{array}{c}\text { PCT } \\
(\mathrm{ng} / \mathrm{mL})\end{array}$ & Reference \\
\hline $\mathrm{F}$ & 14 & 633 & 7.04 & 3.3 & 25,800 & 8.4 & 82.94 & 9 \\
$\mathrm{~F}$ & 15 & 601 & 7.00 & 4.3 & 24,600 & 5.5 & 13.13 & 9 \\
$\mathrm{~F}$ & $\mathrm{~N} / \mathrm{A}$ & 522 & $\mathrm{~N} / \mathrm{A}$ & $\mathrm{N} / \mathrm{A}$ & $\mathrm{N} / \mathrm{A}$ & $\mathrm{N} / \mathrm{A}$ & 1.72 & 10 \\
$\mathrm{~F}$ & 34 & 539 & 6.91 & 2.1 & 21,800 & 0.06 & 12.4 & 11 \\
$\mathrm{~F}$ & 42 & 1,177 & 6.94 & 4.6 & 19,910 & 0.31 & 30.47 & 11 \\
$\mathrm{~F}$ & 32 & 623 & 6.80 & 1.6 & 26,510 & 0.25 & 8.81 & 11 \\
$\mathrm{~F}$ & 73 & 1,044 & 7.06 & 2.8 & 18,900 & 2.08 & 6.87 & 11 \\
$\mathrm{M}$ & 59 & 767 & 7.019 & 4.8 & 14,530 & 6.38 & 62.84 & $\begin{array}{c}\text { The present } \\
\text { case }\end{array}$ \\
\hline
\end{tabular}

CRP: C-reactive protein, DKA: diabetic ketoacidosis, PCT: procalcitonin, WBC: white blood cells

10th day. The PCT levels decreased to $29.6 \mathrm{ng} / \mathrm{mL}$ on the 8 th day. The patient's blood glucose levels stabilized, and his general condition improved; therefore, he was discharged on the 12th day. After discharge, he did not develop any infectious disease and did not experience a recurrence of DKA.

\section{Discussion}

PCT has higher sensitivity and specificity than CRP for distinguishing between infectious and non-infectious diseases. The PCT levels can help to differentiate between bacterial and viral infections with a high sensitivity (92\%) (4). PCT is normally synthesized in thyroid $\mathrm{C}$ cells, as a precursor of calcitonin (7). However, in severe infections caused by bacteria, parasites, and fungi, inflammatory cytokines are produced by the action of bacterial cells and toxins. These cytokines act on organs, such as lungs, kidneys, liver, adipose tissue, and muscles, promoting PCT production (8).

However, serious trauma, surgical invasion, and severe burns, Plasmodium infection, acute respiratory distress syndrome (ARDS) can also lead to elevated PCT levels, and caution is required when interpreting PCT findings in such cases (5). Several studies have reported that DKA enhances cytokine production (1-3). Moreover, hyperglycemia also enhances cytokine production (9). Hence, DKA leads to the production of inflammatory cytokines and an increase in the PCT levels.

Ivaska et al. reported that when children with type $1 \mathrm{DM}$ develop DKA, the PCT levels are high despite the absence of infection (10). Two studies have reported a PCT elevation 
after DKA in adults with type 1 DM $(10,11)$. Information regarding these eight previously reported cases is presented in Table 2. Except for our case, all cases of PCT elevation due to DKA were reported in women, and the median age of the patients was 34 years (range, 14-73 years), which was relatively low. This is likely because women have a stronger immune response than men do (12), and younger individuals in general show higher cytokine production. It is also widely considered that DKA is more likely to occur in young people (13).

The CRP levels were slightly elevated at $3.28 \pm 3.17 \mathrm{mg} /$ $\mathrm{dL}$, but the PCT levels were very high at $26.29 \pm 26.57 \mathrm{ng} /$ $\mathrm{mL}$. However, the level of inflammatory cytokines has not been examined in any previous studies, and it was not possible to prove that DKA enhances PCT production via inflammatory cytokines. Moreover, the number of reported cases is small, and many more cases should be examined and analyzed to elucidate the relationship between inflammatory cytokines and DKA.

In addition, the standard threshold for PCT is slightly higher in patients undergoing HD. Kubo et al. reported that the median PCT level before dialysis in such patients was $0.23 \mathrm{ng} / \mathrm{mL}$, which was higher than that in healthy participants (14). Trimarchi et al. reported that the 95th percentile of PCT levels in 45 uninfected patients on HD was $0.8 \mathrm{ng} /$ $\mathrm{mL}$, which is the upper limit of the reference value (15). While the PCT level in such patients can be slightly higher than that in healthy individuals, the PCT levels in our case were markedly high at $62.84 \mathrm{ng} / \mathrm{mL}$, and no serious bacterial infection was observed. Although candidiasis and aspergillosis antigen tests were not performed, the two conditions were deemed unlikely because the clinical course and findings were not in accordance with either of the two conditions. Moreover, $\beta$-D-glucan was negative $(5.2 \mathrm{pg} / \mathrm{mL})$, and there were no characteristic findings on CT. Since the patient did not have respiratory distress, and pulmonary edema was not detected on chest CT, ARDS was excluded. With no history of overseas travel, Plasmodium infection was unlikely. Although non-severe pneumonia may raise the PCT levels, DKA was strongly suspected to be the main cause of the PCT elevation. In addition, it has been reported that PCT decreases with an improvement in acute hyperglycemia (16); however, the transition trajectory of the PCT levels among DKA patients has not been clarified. In our case, the improvement of DKA was also associated with a reduction in the PCT levels to $29.6 \mathrm{ng} / \mathrm{mL}$, further supporting their DKA-dependent increase. In contrast, Cipriano et al. reported that "PCT returned to normal values $(<0.5 \mathrm{ng} / \mathrm{mL})$ after 3 days of hospitalization, thus reflecting the half-life of the protein." (6). The decline in the PCT level was slow in our case. Meisner et al. suggested that plasma clearance of PCT may be delayed in patients with renal dysfunction (17). While HD will gradually eliminate PCT, our patient could not attain the urinary excretion of procalcitonin because he was anuric. It was suggested that the rate of PCT elimination was slow by HD and offline-HDF alone.
The PCT removal rate was found to be $53.7 \%$ in a single HD using PES membrane (14). Nevertheless, there are no reports of PCT removal rates of HDF. The molecular weight of PCT is approximal $13 \mathrm{kDa}$, which is similar to that of $\beta 2$ microglobulin. Online HDF can achieve a $46 \%$ higher $\beta 2$ microglobulin removal rate when compared with HD (18) suggesting that the first has a better PCT removal rate than the latter. However, he received offline-HDF, and the PCT removal rate was not as high as that of the online-HDF, indicating that the decline in the PCT level was slow. One limitation associated with this report was that the cause of PCT elevation was not only DKA, but pneumonia was also slightly involved.

\section{Conclusion}

Bacterial infections often cause DKA which may elevate the PCT levels. However, DKA in the absence of bacterial infection can also increase the PCT levels. Therefore, in DKA, it is necessary to carefully determine whether PCT is elevated because of bacterial infection or due to DKA itself. In patients on HD, the rate of PCT decline is slower. Further studies are thus needed to determine the transition of PCT in DKA patients on HD.

\section{The authors state that they have no Conflict of Interest (COI).}

\section{References}

1. Dalton RR, Hoffman WH, Passmore GG, Martin SL. Plasma Creactive protein levels in severe diabetic ketoacidosis. Ann Clin Lab Sci 33: 435-442, 2003.

2. Hoffman WH, Burek CL, Waller JL, Fisher LE, Khichi M, Mellick LB. Cytokine response to diabetic ketoacidosis and its treatment. Clin Immunol 108: 175-181, 2003.

3. Karavanaki K, Karanika E, Georga S, et al. Cytokine response to diabetic ketoacidosis (DKA) in children with type 1 diabetes (T1 DM). Endocr J 58: 1045-1053, 2011.

4. Simon L, Gauvin F, Amre DK, Saint-Louis P, Lacroix J. Serum procalcitonin and C-reactive protein levels as markers of bacterial infection: a systematic review and meta-analysis. Clin Infect Dis 39: 206-217, 2004.

5. Christ-Crain M, Müller B. Procalcitonin in bacterial infections-hype, hope, more or less? Swiss Med Wkly 135: 451-460, 2005.

6. Cipriano A, Rebelos E, Park N, Santini M. Moderate increase of serum levels of procalcitonin in diabetic ketoacidosis. Neth $\mathrm{J}$ Med 76: 454, 2018.

7. Becker KL, Nylén ES, White JC, Müller B, Snider RH Jr. Clinical review 167: Procalcitonin and the calcitonin gene family of peptides in inflammation, infection, and sepsis: a journey from calcitonin back to its precursors. J Clin Endocrinol Metab 89: 15121525, 2004.

8. Linscheid P, Seboek D, Nylen ES, et al. In vitro and in vivo calcitonin I gene expression in parenchymal cells: a novel product of human adipose tissue. Endocrinology 144: 5578-5584, 2003.

9. Jafar N, Edriss H, Nugent K. The effect of short-term hyperglycemia on the innate immune system. Am J Med Sci 351: 201-211, 2016.

10. Ivaska L, Elenius V, Mononen I, Ruuskanen O, Peltola V. Discrepancies between plasma procalcitonin and C-reactive protein levels are common in acute illness. Acta Paediatr 105: 508-513, 2016.

11. Anno T, Shigemoto R, Kawasaki F, et al. Marked elevation of 
plasma procalcitonin levels in patients with diabetic ketoacidosis: a possible useful diagnostic biomarker. Diabetes Metab 46: 504-505, 2020.

12. Chrousos GP. Stress and sex versus immunity and inflammation. Sci Signal 3: pe36, 2010.

13. Wolfsdorf JI, Glaser N, Agus M, et al. ISPAD Clinical Practice Consensus Guidelines 2018: Diabetic ketoacidosis and the hyperglycemic hyperosmolar state. Pediatr Diabetes 19: 155-177, 2018.

14. Kubo S, Iwasaki M, Horie M, et al. Biological variation of procalcitonin levels in hemodialysis patients. Clin Exp Nephrol 23: 402408, 2019.

15. Trimarchi H, Dicugno M, Muryan A, et al. Pro-calcitonin and inflammation in chronic hemodialysis. Medicina (B Aires) 73: 411416, 2013.

16. Aksu NM, Aksoy DY, Akkaş M, et al. 25-OH-Vitamin D and pro- calcitonin levels after correction of acute hyperglycemia. Med Sci Monit 19: 264-268, 2013.

17. Meisner M, Lohs $T$, Huettemann E, Schmidt J, Hueller M, Reinhart K. The plasma elimination rate and urinary secretion of procalcitonin in patients with normal and impaired renal function. Eur J Anaesthesiol 18: 79-87, 2001.

18. Lornoy W, Becaus I, Billiouw JM, Sierens L, van Malderen P. remarkable removal of beta-2-microglobulin by on-line hemodiafiltration. Am J Nephrol 18: 105-108, 1998.

The Internal Medicine is an Open Access journal distributed under the Creative Commons Attribution-NonCommercial-NoDerivatives 4.0 International License. To view the details of this license, please visit (https://creativecommons.org/licenses/ by-nc-nd/4.0/).

(C) 2021 The Japanese Society of Internal Medicine Intern Med 60: 1231-1235, 2021 